\title{
Brief report \\ Characterization of hobo element copy number and integrity in Brasilian populations of Drosophila melanogaster
}

\author{
MARIANGELA TORREGLOSA RUIZ and CLAUDIA MARCIA APARECIDA CARARETO \\ Departamento de Biologia, Universidade Estadual Paulista - UNESP, Rua Cristóvão Colombo, 2265, Jardim \\ Nazaré 15054-000 São José do Rio Preto, SP, Brasil. E-mail: carareto@bio.ibilce.unesp.br
}

Received February 20, 2003. Accepted April 26, 2003

\begin{abstract}
We have determined the copy number and the presence of full-size hobo transposable elements in eight Brasilian strains of Drosophila melanogaster. Genomic DNA was digested with AvaII and XhoI restriction enzymes, respectively, and probed with a $963 \mathrm{bp}$ sequence of the hobo element. Variable numbers of full-sized and defective elements were detected in all strains. The range of the copy number was $22.13 \pm 4.52$. Blots showed the presence of a $2.6 \mathrm{~kb}$ fragment, corresponding to the complete element, in all strains exception of one and the $1.0 \mathrm{~kb}$ sequence, correponding to the $T h 1$ and Th2 repressor elements. There was neither association among copy numbers of hobo elements and latitude nor the mean annual temperatures in the original geographical region of each strain.
\end{abstract}

Among the mobile elements that have been studied in Drosophila melanogaster, the $P, I$ and hobo elements can produce a number of germline abnormalities referred to as hybrid dysgenesis (KIDWELL et al. 1977). These anomalies are associated with the mobilization of a transposable element through the interaction of chromosomal, cytoplasmic and environmental factors typical of each family (ENGELS 1988). The hobo family consists of autonomous elements and some smaller deletions derivatives, defective elements. The autonomous element contains 2959 bp, possesses two inverted terminal repeats of $12 \mathrm{bp}$ (BLACKMAN et al. 1987) and two ORFs: a large one (ORF1) that extends from nucleotide position 307 to 2289, and a small upstream ORF (ORF0) that extends from nucleotide position 208 to 303 (MCGINNis et al. 1983; Streck et al. 1986; CAlvi et al. 1991).

There are two classes of $D$. melanogaster strains as defined by their hobo elements (BLACKMAN and GELBART 1989). H strains contain full-sized and numeous smaller derivatives, whereas E strains lack all such elements but possesses some weak homologous sequences (STRECK et al. 1986). In most laboratory strains examined thus far, the number of complete elements is low, about 2 to 10 copies per haploid genome, while smaller deleted elements, belonging to different classes appear to be more numerous, from 30 to 75 (Periquet et al. 1989). In addition to the $\mathrm{H}$ and $\mathrm{E}$ classes, some strains contain only internally deleted, and presumably non-autonomous elements (DH strains).

D. melanogaster strains, which were captured in different geographical surveys, showed that the hobo element started to be widely present in nature $(\mathrm{H}$ strains) since the 1950s and it is now found in all wild populations around the world (PERIQUET et al. 1989).
Strains captured prior to the fifties have no homologous hobo sequences (E strains). We do not have any information about the number and the occurrence of complete and defective hobo elements Brasilian populations of $D$. melanogaster. We here report data on eight Brasilian populations.

\section{MATERIAL AND METHODS}

\section{Strains}

Drosophila melanogaster isofemale lines were set up from strains derived from collections made in eight Brasilian regions. The strains are described below according to the northern-southern geographical occurrence and denoted by the abbreviation of the Brazlina state in which the parental flies were captured: MA (Maranhão, 2.31 ${ }^{\circ}$ Slat), set up with seven females collected in 1995; PI (Piauí, 5.09 Slat), set up with 15 females collected in 1996; MG (Minas Gerais, $18.20^{\circ}$ Slat), set up with 10 females collected in September 1995; SP (São Paulo, $20.49^{\circ}$ Slat), set up with eight females collected in 1995; PR (Paraná, $23.25^{\circ}$ Slat), set up with five females collected in 1996; SC (Santa Catarina, 26.18 Slat), set up with two females collected in 1996; $\mathrm{RS}_{1}$ (Rio Grande do Sul, $29.41^{\circ}$ Slat), set up with five females collected in 1999; and $\mathrm{RS}_{2}$ (Rio Grande do Sul, $30.02^{\circ}$ Slat), set up with five females collected in 1995. MA and PI were, accordingly, equatorial strains, coming from regions with mean annual temperature above $22^{\circ} \mathrm{C}$ and up to $40^{\circ} \mathrm{C}$ in the summer. SP came from a population in southeastern Brasil with mean annual temperatures above $22^{\circ} \mathrm{C}$ with lows rarely below $15^{\circ} \mathrm{C}$ in the winter. $\mathrm{MG}$ originated from a mountainous region in southeastern Brasil, with moderate temperatures in the summer and average temperatures below $12^{\circ} \mathrm{C}$ in 
winter and fall. The southern strains PR, SC, $\mathrm{RS}_{1}$ and $\mathrm{RS}_{2}$ originated from subtropical regions characterized by well-defined seasons with temperatures ranging from $2^{\circ} \mathrm{C}$ to $15^{\circ} \mathrm{C}$ in the winter and $25^{\circ} \mathrm{C}$ to $35^{\circ} \mathrm{C}$ in the summer. The strain Drosophila melanogaster $23.5 / \mathrm{CyL}\left(\mathrm{H}^{+}\right)$was used as a positive control for the presence of hobo element.

\section{Southern blot analysis}

Genomic DNA was isolated from pools of about fifty individuals of each line and $5 \mu \mathrm{g}$ of it were digested with the endonucleases $A v a \mathrm{II}$ and XhoI in order to investigate the copy number and the integrity of hobo elements, respectively. AvaII recognizes a unique site in the hobo sequence and produces fragments of different lengths that can be derived from deleted or full-sized elements. Xho I cuts a full-sized hobo at two sites (285 and 2849) producing an internal fragment with $2564 \mathrm{bp}$. In both cases, the membranes were probed with a $963 \mathrm{bp}$ sequence of $D$. melanogaster hobo element amplified from the pHX4 (a plasmid that contains the $2.6 \mathrm{XhoI}$ fragment of Drosophila melanogaster hobo element), using the primers 651 (5'-CACCTCCAATTTATCCCGCC-3') and 1598 (5'GGATGGCAATACGAAGC-3'). The DNA fragments were electrophoresed, transferred to nylon membranes, and fixed. The ECL hybridization buffer (Amersham Pharmacia Biotech do Brasil ${ }^{\mathrm{TM}}$ ) was used. The membrane was washed for $40 \mathrm{~min}$ in primary buffer $(6 \mathrm{M}$ urea, $0.4 \mathrm{SDS}$ and $0.5 \mathrm{M} \times \mathrm{SSC})$, at $42^{\circ} \mathrm{C}$, and for $10 \mathrm{~min}$ in secondary buffer $(2 \times$ $\mathrm{SSC})$ at room temperature.

\section{Statistical analysis}

Correlatin analysis was performed to evaluate the influence of latitude on copy number and of each strain. Two classes of strains were formed and the t-Student test was used to investigate the association between the copy numbers of hobo elements and mean annual temperatures in the original geographical region of each one. The first strain class included the equatorial strains MA and PI and the southeastern strain SP; the second class included the southeastern strain MG and the southern strains PR, SC, $\mathrm{RS}_{1}$ and $\mathrm{RS}_{2}$.

\section{RESULTS AND DISCUSSION}

The AvaII digests showed that the total number of hobo elements is variable among the eight $D$. melanogaster Brasilian strains $(\mathrm{MA}=13 ; \mathrm{PI}=26$; $\mathrm{MG}=20 ; \quad \mathrm{SP}=22 ; \quad \mathrm{PR}=24 ; \quad \mathrm{SC}=21 ; \quad \mathrm{RS}_{1}=23 ;$ $\mathrm{RS}_{2}=28$ ), with mean value equals to $22.13 \pm 4.52$.

The natural strains have many full-sized and defective sequences, but the defective sequences occur in comparatively larger numbers and seem to act as repressors of transposition. All lines, excepting MA, showed the $2.6 \mathrm{~kb}$ fragment expected from the digestion of the full-sized hobo by Xho I, with several signal intensities (Fig. 1). The presence of this sequence, that embraces about $90 \%$ of the complete element, is a good estimation of the occurrence of at least one full-sized element in all the strains. All the strains carry defective copies with variable sizes and densities. The occurrence of the $2.6 \mathrm{~kb}$ fragment, which indicates potentially full-size hobo elements in the genome, and the smaller fragments, lead us to the conclusion that the Brasilian strains correspond to $\mathrm{H}$ lines of Streck et al. (1986). E lines were not found among the eight strains.

At least three kinds of defective hobo sequences (Th1, Th2 and hobo $v g^{a l}$ ) have been found in all Eurasian, American and French populations of $D$. melanogaster. They seem to act as repressors of transposition (Periquet et al. 1989; Pascual and PeriQUET 1991). When cleaved with XhoI, the element Th1 generates a fragment of $1.11 \mathrm{~kb}$; the Th2 a fragment of $1.09 \mathrm{~kb}$ and the $v g^{a l}$ element produces a fragment of $1.47 \mathrm{~kb}$. A fragment measuring about 1.0 $\mathrm{kb}$, corresponding to the Th1 and Th2 elements, occurs in all the strains. The presence of these repressors might be related to the low level of hybrid dysgenesis presented by these strains in diagnostic crosses using the 23.5/Cy L strain (Vetorazzi 1998).

The syndrome of hybrid dysgenesis caused by the hobo transposition includes thermosensitive sterility (at $25^{\circ} \mathrm{C}$ ) due to atrophy of the gonads (gonadal dysgenesis), chromosomal breaks and rearrangements, mutations and male recombination (BLACKMAN et al. 1987; YANNOPOULOS et al. 1987; BAZIN et al. 1999). The frequency of these genetic abnormalities increases in dysgenic flies reared above $25^{\circ} \mathrm{C}$. This observation implies that, in addition to the occurrence of repressors, temperature can also impose selective pressure and might regulate hobo element copy number in natural populations from regions with high temperatures throughout the year. To evaluate this hypothesis, the hobo copy numbers of strains from tropical or temperate climates were compared. The mean copy numbers of strains of tropical climate (MA, PI, SP) was $20.33 \pm 6.66$, while the mean of those from temperate climate strains (MG, $\mathrm{PR}, \mathrm{SC}, \mathrm{RS}_{1}$ and $\mathrm{RS}_{2}$ ) was $23.20 \pm 3.11$. The difference was not significant $\left(t_{7}=0.70 ; p>0.05\right)$. As for the results obtained in the evaluation of $P$ element copy number in these very same strains, the lines derived from equatorial and tropical populations showed significantly lower numbers of $P$ elements than the ones from temperate regions (RuIz 2002). In the same way the correlation among latitudes of the 


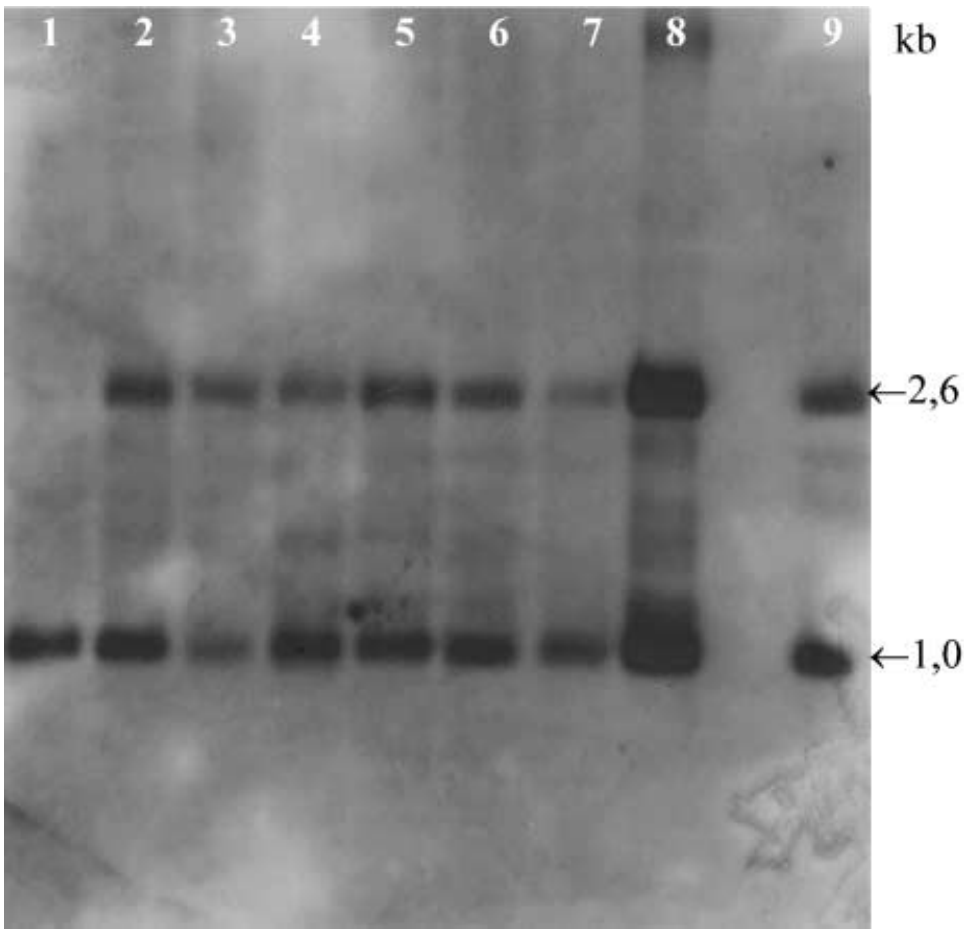

Fig. 1. Southern blot analysis of genomic DNA of eight strains of $D$. melanogaster digested with XhoI and probed with a 963 bp sequence of D. melanogaster hobo element amplified from the $\mathrm{pHX} 4$ plasmid. The numbers correspond to strains collected from north to south (1: MA; 2: PI; 3:MG; 4: SP; 5: PR; 6: $\mathrm{SC}$; 7: $\mathrm{RS}_{1}$; 8: $\mathrm{RS}_{2}$; and 9: the positive control 23.5/CyL). Xho I restriction fragments are indicated: $2.6 \mathrm{~kb}$ fragment of the full-size hobo element; $1.0 \mathrm{~kb}$ fragment common to all strains.

geographical origins of the strains and the hobo copy numbers in each strain $(\mathrm{r}=0.522 ; \mathrm{t}=1.49 ; \mathrm{p}>0.05)$ was not significant. This lack of relationship between hobo phenotypes and geographical origin of the strains had already been observed by Boussy et al. (1988) who did not find significant differences between hobo phenotypes in D. melanogaster of the tropical northern and the temperate southern Australian ones. Our results, as well as those of Boussy et al. (1988), could be explained by the circumstance that transposition of hobo occurs at relatively low temperatures $\left(25^{\circ} \mathrm{C}\right)$. The lack of significant differences might reflect absence of selection for number of copies regarding to the environmental temperature.

\section{ACKNOWLEDGEMENTS}

The authors thank I. Boussy, V. L. S. V. Gaiesky, C. R. Vilela, E. L. S. Loreto, S. R. P. Martins, Z. M. da Silva, A. S. Lapenta and V. C. R. Vetorazzi for providing us with the strains of $D$. melanogaster. Funds supporting this study were provided by FAPESP, CNPq and CAPES.

\section{REFERENCES}

Bazin, C., Denis, B., Capy, P. et al. 1999. Characterization of permissity for hobo-mediated gonadal dysgenesis in Drosophila melanogaster. - Mol. Gen. Genet 261: 480486.

Blackman, R. K. and Gelbart, W. M. 1989. The transposable element hobo of Drosophila melanogaster. - In: Berg, D. E. and Howe, M. M. (eds), Mobile DNA. Am. Soc. Microbiol. Publications, Baltimore, pp. 523-530.

Blackman, R. K., Grimaila, R., Koehler, M. M. D. and Gelbart, W. M. 1987. Mobilization of hobo elements residing within the decapentaplegic gene complex: suggestion of a new hybrid dysgenesis system in Drosophila melanogaster. - Cell 49: 497-505.

Boussy, I. A., Healy, M. J., Oakeshott, J. G. and Kidwell, M. G. 1988. Molecular analysis of the P-M gonadal dysgenesis cline in eastern Australian Drosophila melanogaster. - Genetics 119: 889-902.

Calvi, B. R., Hong, T. J., Findley, S. D. and Gelbart, W. M. 1991. Evidence for a common evolutionary origin of inverted repeat transposon in Drosophila and plants: hobo, activator, and Tam3. - Cell 66: 465-471.

Engels, W. R. 1988. P elements in Drosophila. - In: Berg, D. E. and Howe, M. M. (eds), Mobile DNA. Am. Soc. Microbiol. Publications, Baltimore, pp. 437-484.

Kidwell, M. G., Kidwell, J. F. and Sved, J. A. 1977. Hybrid 
dysgenesis in Drosophila melanogaster. - Proc. Natl Acad. Sci. USA 80: 1655-1659.

McGinnis, W., Shermoen, A. W. and Beckendorf, S. K. 1983. A transposable element inserted just 5'prime to a Drosophila glue protein gene alters expression and chromatin structure. - Cell 34: 75-84.

Pascual, L. and Periquet, G. 1991. Distribution of hobo transposable elements in natural populations of Drosophila melanogaster. - Mol. Biol. Evol. 8: 282-296.

Periquet, G., Hamelin, M. H., Bigot, Y. and Lepissier, A. 1989. Geographical and historical patterns of distribution of hobo elements in Drosophila melanogaster populations. - J. Evol. Biol. 2: 223-229.

Ruiz, M. T. 2002. Analysis of the integrity and number of copies of hobo and $P$ transposable elements in Brazilian
Drosophila melanogaster populations. - Gen. Mol. Biol. 25: 119.

Streck, R. D., MacGaffey, J. E. and Beckendorf, S. K. 1986. The structure of hobo transposable elements and their insertion sites. - EMBO J. 5: 3615-3623.

Vetorazzi, V. C. R. 1998. Hybrid dysgenesis induced by $P$ and hobo transposable elements in Drosophila melanogaster strains from Brazil. - Gen. Mol. Biol. 21: 291-292.

Yannopoulos, G., Stamatis, N., Monastirioti, M. et al. 1987. hobo is responsible for the induction of hybrid dysgenesis by strains of Drosophila melanogaster bearing the male recombination factor $23.5 M R F$. - Cell 49: 487-495. 